\title{
Surgical management for abnormal head position in nystagmus: the augmented modified Kestenbaum procedure
}

\author{
LEONARD B. NELSON, LAURI D. ERVIN-MULVEY, JOSEPH H. CALHOUN, \\ ROBISON D. HARLEY, AND MARK S. KEISLER
}

From the Department of Pediatric Ophthalmology and Strabismus, Wills Eye Hospital, Philadelphia, Pennsylvania, USA

SUMmary Patients with nystagmus and an eccentric null point in lateral gaze may assume an abnormal head position to maximise visual acuity. Surgical procedures for this condition can result in significant undercorrection of the head turn. A follow-up of 15 patients for an average of 33 months revealed a sustained improvement in head position with the use of the augmented modified Kestenbaum procedure.

The surgical procedures for the correction of abnormal head positions in patients with congenital nystagmus began with the independent reports of Anderson, Goto, and Kestenbaum in the early 1950 s. ${ }^{1-3}$ In an attempt to explain the abnormal head position Anderson postulated that the muscles acting in the slow phase of the nystagmus overacted. He advised as treatment a weakening procedure for the two yoke muscles involved. Goto believed that there was an underaction of the muscles acting in the fast phase of the nystagmus; he advised that bilateral resection of these two muscles be performed. Kestenbaum advocated a combined recession/resection procedure for all four horizontal rectus muscles. He recessed or resected the two muscles of each eye from $4 \mathrm{~mm}$ to 10 $\mathrm{mm}$. Parks ${ }^{4}$ subsequently suggested a modified Kestenbaum procedure. He advocated horizontal rectus muscle surgery of $5 \mathrm{~mm}, 6 \mathrm{~mm}, 7 \mathrm{~mm}$, and 8 $\mathrm{mm}$, with a total of $13 \mathrm{~mm}$ of surgery performed on each eye. Surgery of $5 \mathrm{~mm}$ or $6 \mathrm{~mm}$ was always performed on the medial rectus muscles, the former with a recession, the latter with a resection. Surgery of $7 \mathrm{~mm}$ or $8 \mathrm{~mm}$ was performed on the lateral rectus muscles, again the former with a recession and the latter with a resection. At that time Parks believed that these amounts of surgery were the maximum amounts which could be performed to preserve full ductions.

Correspondence to Dr Leonard B. Nelson, Department of Pediatric Ophthalmology, Wills Eye Hospital, 9th and Walnut Streets, Philadelphia, PA 19107, USA.
Because of the high rates of recurrence and undercorrection following the modified Kestenbaum procedure Calhoun and Harley recommended increasing the amount of surgery by $40 \% .^{5}$ The Parks measurements of $5 \mathrm{~mm}, 6 \mathrm{~mm}, 7 \mathrm{~mm}$, and $8 \mathrm{~mm}$ were augmented by $40 \%$, resulting in surgery of $7 \mathrm{~mm}, 8.4$ $\mathrm{mm}, 9.8 \mathrm{~mm}$, and $11.2 \mathrm{~mm}$ on the rectus muscles. This maintained the Parks ratio for the modified Kestenbaum procedure, which had been shown by Calhoun and Harley to preserve binocular function postoperatively. ${ }^{5}$ From 1973 until the present time we have used the modified Kestenbaum procedure, augmented by either $40 \%$ or $60 \%$ (augmentation of $60 \%$ results in surgery of $8 \mathrm{~mm}, 9.6 \mathrm{~mm}, 11.2 \mathrm{~mm}$, and $12.8 \mathrm{~mm}$ ) as the procedure of choice for correcting the abnormal head position in congenital nystagmus. We report here on the long-term surgical results of the augmented modified Kestenbaum procedure.

\section{Subjects and methods}

The patients in this study were selected from those being treated at the Pediatric Ophthalmology Department of Wills Eye Hospital. A total of 17 patients underwent the augmented modified Kestenbaum procedure from 1973 to 1982 . Two of these cases were excluded from the series because follow-up times were less than six months. All of the patients included had at least an eight-month followup. The longest follow-up was 105 months; the average was 33 months. Twelve of the patients were males and three were females. 

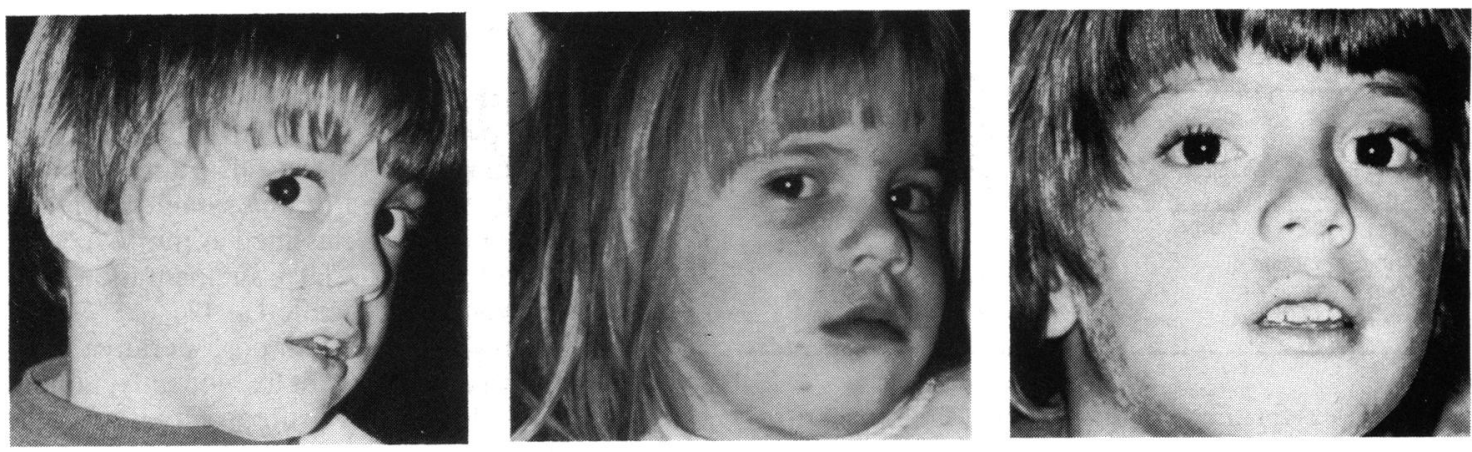

Fig. 1 Left: Estimated head turn of $45^{\circ}$. Centre: Estimated head turn of $30^{\circ}$. Right: Estimated head turn of $15^{\circ}$.

The indication for surgical intervention in patients with congenital nystagmus was an unacceptable head position $\left(30^{\circ}\right.$ or greater) that was not correctable by glasses. Preoperative head turns were estimated and were assessed while the patient fixated on a small, distant object (Fig. 1). The head position assumed by the patient was then estimated by the observer (either Dr Calhoun or Dr Nelson) to the nearest $15^{\circ}$ preoperatively and $5^{\circ}$ postoperatively. Surgical intervention was designed to correct the maximum estimated distance deviation. Table 1 indicates preoperative and postoperative head turns for distant fixation only.

All patients who underwent surgery had a complete ophthalmological examination. The mean age at the time of surgery was $9 \cdot 8$ years. The range was from $3 \frac{1}{2}$ to 30 years and the median age was 5 years. In 14 of the 15 patients nystagmus was noted shortly after birth. Patient 2 developed nystagmus after a road accident in which he suffered a brain stem injury.
Patient 5 had tyrosinase-positive oculocutaneous albinism, while patient 10 had unilateral microphthalmos with severely compromised vision. Patient 15 had anisometropic amblyopia without strabismus. Preoperative visual acuities were measured while the patients maintained their greatest degree of head turn (Table 1). None of the patients had strabismus before operation.

The surgical technique was performed in order to move the eyes in the direction that the face was turned (toward the direction of the quick phase of the nystagmus). The measurement for the caliper placement was rounded off to the nearest half millimeter for both the $40 \%$ and $60 \%$ augmented procedures.

\section{Results}

The results of the surgery are summarised in Table 2 . Of the eight patients who underwent the modified Kestenbaum procedure with a $40 \%$ augmentation

Table 1 Preoperative and postoperative head turns

\begin{tabular}{|c|c|c|c|c|c|c|c|}
\hline \multirow[t]{3}{*}{ Patient } & \multirow{3}{*}{$\begin{array}{l}\text { Age } \\
\text { (years) }\end{array}$} & \multirow{2}{*}{\multicolumn{2}{|c|}{$\begin{array}{l}\text { Pre- and postoperative } \\
\text { visual acuities }\end{array}$}} & \multicolumn{2}{|l|}{ Head turn } & \multirow{3}{*}{$\begin{array}{l}\text { Procedure \% } \\
\text { augumentation }\end{array}$} & \multirow{3}{*}{$\begin{array}{l}\text { Follow-up } \\
\text { (months) }\end{array}$} \\
\hline & & & & \multirow{2}{*}{$\begin{array}{l}\text { Preoperative } \\
\text { measurement }\end{array}$} & \multirow{2}{*}{$\begin{array}{l}\text { Postoperative } \\
\text { measurement }\end{array}$} & & \\
\hline & & $O D$ & $O S$ & & & & \\
\hline 1 & 30 & $20 / 50$ & $20 / 50$ & R $30^{\circ}$ & $0^{\circ}$ & +40 & 25 \\
\hline 2 & 11 & $20 / 25$ & $20 / 25$ & L $30^{\circ}$ & $0^{\circ}$ & +40 & 38 \\
\hline 3 & 5 & $20 / 60$ & $20 / 60$ & L $30^{\circ}$ & $0^{\circ}$ & +40 & 56 \\
\hline 4 & $31 / 2$ & $20 / 30$ & $20 / 30$ & L $30^{\circ}$ & $0^{\circ}$ & +40 & 8 \\
\hline 5 & 5 & $20 / 100$ & $20 / 100$ & L $45^{\circ}$ & L $15^{\circ}$ & +40 & 38 \\
\hline 6 & 5 & $20 / 40$ & $20 / 40$ & R $45^{\circ}$ & R $\quad 5^{\circ}$ & +40 & 30 \\
\hline 7 & $41 / 2$ & $20 / 40$ & $20 / 40$ & R $45^{\circ}$ & R $15^{\circ}$ & +40 & 8 \\
\hline 8 & 17 & $20 / 80$ & $20 / 80$ & R $45^{\circ}$ & L $15^{\circ}$ & +40 & 12 \\
\hline 9 & 7 & $20 / 60$ & $20 / 70$ & R $45^{\circ}$ & R $10^{\circ}$ & +60 & 21 \\
\hline 10 & 3 & $20 / 40$ & HM & R $45^{\circ}$ & $0^{\circ}$ & +60 & 40 \\
\hline 11 & 14 & $20 / 50$ & $20 / 50$ & R $45^{\circ}$ & R $15^{\circ}$ & +60 & 30 \\
\hline 12 & 3 & $20 / 40$ & $20 / 40$ & L $45^{\circ}$ & $0^{\circ}$ & +60 & 34 \\
\hline 13 & 5 & $20 / 60$ & $20 / 60$ & R $45^{\circ}$ & $0^{\circ}$ & +60 & 40 \\
\hline 14 & 4 & $20 / 60$ & $20 / 60$ & L $45^{\circ}$ & L $\quad 15^{\circ}$ & +60 & 105 \\
\hline 15 & 11 & $20 / 400$ & $20 / 30$ & L $45^{\circ}$ & $0^{\circ}$ & +60 & 33 \\
\hline
\end{tabular}

${ }^{*} \mathrm{HM}=$ Hand motion 
Table 2 Results of the augmented modified Kestenbaum procedure

\begin{tabular}{lllll}
\hline Procedure & $\begin{array}{l}\text { Number } \\
\text { of patients } \\
\text { cured }\end{array}$ & $\begin{array}{l}\text { Number } \\
\text { of patients } \\
\text { improved }\end{array}$ & $\begin{array}{l}\text { Total } \\
\text { number of } \\
\text { patients }\end{array}$ & $\begin{array}{l}\text { Percentage } \\
\text { cured }\end{array}$ \\
\hline $\begin{array}{l}\text { Modified } \\
\text { Kestenbaum }+40 \%\end{array}$ & 4 & 4 & 8 & $50 \%$ \\
$\begin{array}{l}\text { Modified } \\
\text { Kestenbaum }+60 \%\end{array}$ & 4 & 3 & 7 & $57 \%$ \\
\hline
\end{tabular}

four $(50 \%)$ were classified as cured of their head turn. 'Cured' by our definition meant that there was no residual head turn at the time of the last ophthalmic evaluation. The remaining four patients $(50 \%)$ were classified as 'improved,' which we defined as having a residual head turn of $15^{\circ}$ or less. Since the indication for surgery is largely for cosmesis, the authors considered a residual head turn of $15^{\circ}$ cosmetically acceptable and not an amount that necessitated an initial surgical correction.

All four patients who were cured of their head turn with a $40 \%$ augmentation had a preoperative
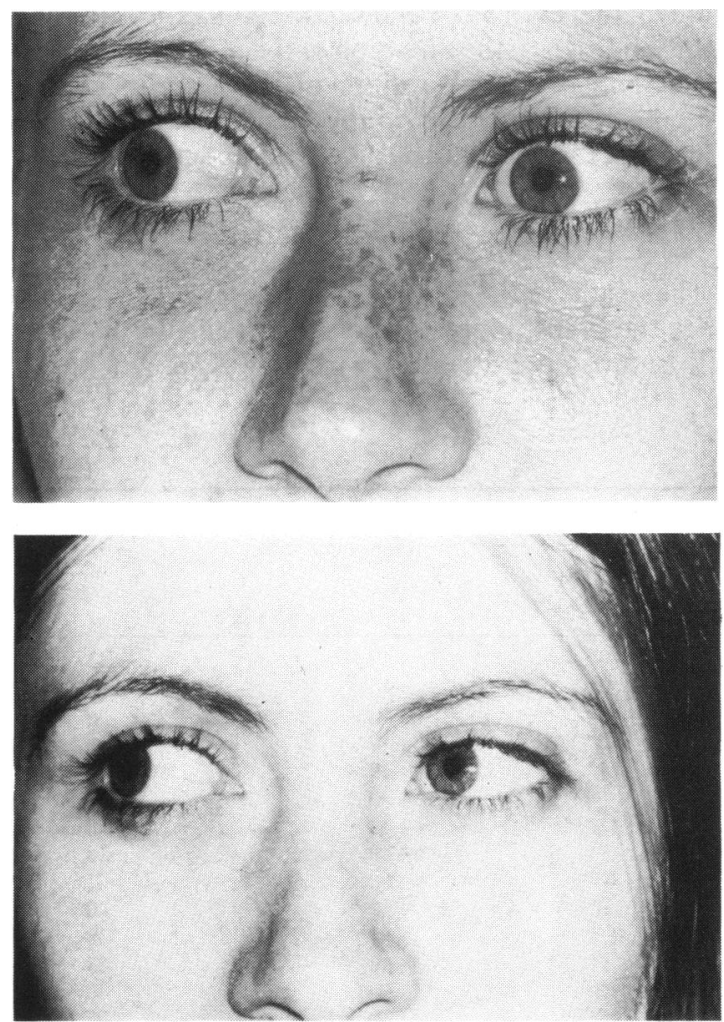

Fig. 2 Above: Preoperative lateral gaze away from the original head turn following a $40 \%$ augmentation. Below: Postoperative gaze. Note moderate restriction of gaze. head turn estimated at $30^{\circ}$. The remaining four patients who improved all had a preoperative head turn estimated at $45^{\circ}$.

Of the seven patients who underwent the modified Kestenbaum procedure with a $60 \%$ augmentation four $(57 \%)$ were classified by the same criterion as cured. Three $(43 \%)$ were classified as improved. All patients who underwent the $60 \%$ augmentation had a preoperative head turn estimated at $45^{\circ}$.

Although preoperative and postoperative head turns were tabulated for distant fixation only, none of the patients evidenced an overcorrection for near fixation after surgery. The distance head turns in our patients were greater than those at near both pre- and postoperatively.

When an attempt to measure the angle of head turning with a perimeter was made, several problems were encountered. First, unless particular attention was paid to maintaining distant fixation by having the patient look over the perimeter, a false underestimate of the head turning resulted. Secondly, it was technically difficult for a child to look over the perimeter. Finally, as a patient gradually turned his head as smaller optotypes were presented at a distance, head movement occurred posteriorly from the chin rest causing a false overestimate of the head turning.

Restriction of motility after operation varied in our series. In the majority of patients this restriction was moderate, with less than $50 \%$ reduction in lateral gaze away from the original head turn (Fig. 2). Although the $60 \%$ augmentation procedure limited motility more than the $40 \%$ augmentation procedure, the amount was not significantly greater.

Our 'cured' rates of $50 \%$ to $57 \%$ and our 'improved' rates of $43 \%$ to $50 \%$ pertain to horizontal head alignment only. Two of the cases (patient 3 and patient 6) showed a vertical torticollis postoperatively, and one case (patient 10) had a head tilt. These head positions were not noted prior to surgery, and no $A$ or $V$ pattern was present either preoperatively or postoperatively in these children.

\section{Discussion}

The abnormal head turn adopted by some patients with congenital nystagmus correlates with the position of minimum ocular excursion and maximum visual acuity. ${ }^{67}$ This position may result in a disfiguring torticollis.

With the advent of the Kestenbaum procedure and the Park modification a surgical correction was made possible for this abnormal head position. The cure rates for this procedure have been modest. In Parks's initial report four of these 10 patients with an average follow-up of 1.5 years were classified as cured ${ }^{4} \mathrm{~A}$ low cure rate was also reported with the modified 
Kestenbaum procedure in the series published by Calhoun and Harley; only two of their 10 patients were cured by this technique. ${ }^{5}$

More recent experience with the modified Kestenbaum procedure has come from Flynn and Dell'Oso. ${ }^{7}$ Their one patient with binocular vision had a heterotropia created after the modified Kestenbaum procedure accompanied by a recurrence of a head turn in the immediate postoperative period. These authors suggest that the modified Kestenbaum procedure is generally inadequate to correct the abnormal head position in congenital nystagmus.

To overcome the high rates of recurrence with the Kestenbaum and modified Kestenbaum procedures several authors have suggested that different amounts of surgery should be performed. Taylor recommended that an $8 \mathrm{~mm}$ to $9 \mathrm{~mm}$ recession of the lateral rectus muscle, and $6 \mathrm{~mm}$ recession of the medial rectus muscle, be performed in conjunction with 6 mm resections of the respective antagonists. ${ }^{8}$ This small surgical modification produced encouraging results in two patients. Kommerell published the results from a series of 28 patients with congenital nystagmus who underwent a Kestenbaum type of operation. 'Sixteen of these patients had an associated strabismus. Of the 12 patients without strabismus six received the traditional Kestenbaum procedure (4 $\mathrm{mm}$ to $5 \mathrm{~mm}$ of surgery on each muscle). Because three of these patients had significant postoperative head turns (greater than $25^{\circ}$ ), Kommerell increased the amount of surgery to $8 \mathrm{~mm}$ for the remaining six patients. These patients had less postoperative head turn $\left(0\right.$ to $\left.15^{\circ}\right)$ after a follow-up period of 4 to 50 months.

In the recent European literature some success has been reported with the use of a Faden or posterior fixation suture, which can be combined with a traditional Kestenbaum procedure. ${ }^{1011}$ The best results from this technique occurred when two separate surgical procedures were used: the first was a Kestenbaum operation, the second was a Faden procedure performed three months later if residual head turn was found. Unfortunately there has been no detailed publication on the long-term surgical results for large numbers of these patients.

The initial report of the modified Kestenbaum procedure augmented by $40 \%$ demonstrated a high rate of success in a small group of patients. ${ }^{5}$ Three of four patients were classified as cured of their abnormal head turn, and the fourth was significantly improved. However, follow-up time was short, so the long-term surgical benefits could not be indicated in this study.

Our series of 15 patients affords a more complete assessment of the augmented modified Kestenbaum procedure. Follow-up time averaged 33 months. A standard amount of surgery (involving either a $40 \%$ or $60 \%$ augmentation) was performed by two of the authors (Drs Calhoun and Nelson).

Four of eight $(50 \%)$ patients who underwent the $40 \%$ augmentation were cured of their abnormal head turn. All four patients had a preoperative head turn estimated at $30^{\circ}$. The remaining four patients who improved with the $40 \%$ augmentation had preoperative head turns estimated at $45^{\circ}$. All seven patients who underwent a $60 \%$ augmentation procedure had a preoperative head turn estimated at $45^{\circ}$; four of seven $(57 \%)$ were cured of the head turn postoperatively.

Patients with nystagmus and an eccentric null point in lateral gaze will assume a head position to maximise visual acuity. These patients essentially have a gaze palsy in the direction of the head turn. Following the $40 \%$ or $60 \%$ augmentation, reduction of lateral gaze away from the original head turn may be as great as $50 \%$. Postoperatively, a gaze palsy is created in the opposite direction. However, in our experience parents and patients preferred the more normal head position and did not complain about the decreased field of rotation. In addition, no strabismus was produced with either the $40 \%$ or $60 \%$ augmented procedure.

Flynn and Dell'Oso (and initially Kestenbaum) reported an increase in visual acuity after a Kestenbaum type of procedure. ${ }^{36} \mathrm{We}$ measured our patients' preoperative visual acuities while they maintained their largest degree of head turn. Therefore in our series of 15 patients we could not demonstrate any improvement in visual acuity postoperatively.

The augmented modified Kestenbaum procedure produces a more sustained surgical correction for the abnormal head position in congenital nystagmus than the Kestenbaum or modified Kestenbaum procedures. We recommend using a $40 \%$ augmentation of the modified Kestenbaum procedure for those patients with $30^{\circ}$ of head turn. For patients with $45^{\circ}$ of head turn we recommend a $60 \%$ augmentation to achieve maximum correction.

This work was made possible in part by grants from Fight for Sight Inc., New York, New York to the Fight for Sight Children's Eye Center of Wills Eye Hospital; it was also supported in part by the Wills Eye Hospital Research Division.

\section{References}

1 Anderson JR. Causes and treatment of congenital eccentric nystagmus. Br J Ophthalmol 1953; 37: 267-80.

2 Goto N. A study of optic nystagmus by the electro-oculogram. Nippon Ganka Gakkai Zasshi (Tokyo) 1954; 58: 851-65 (abstracted in Ophthalmic Lit 1954: 8: 1493).

3 Kestenbaum A. Nouvelle opération de nystagmus. Bull Soc Ophtalmol Fr 1954; 2: 1071-8.

4 Parks MM. Congenital nystagmus surgery. Am Orthop J 1973; 23: 35-9. 
5 Calhoun JH, Harley RD. Surgery for abnormal head position in congenital nystagmus. Trans Am Ophthalmol Soc 1973; 71: $70-87$.

6 Dell'Oso LF, Flynn JT. Congenital nystagmus surgery: a quantitative evaluation of the effects. Arch Ophthalmol 1979; 97: 462-9.

7 Flynn JT, Dell'Oso LF. The effects of congenital nystagmus surgery. Ophthalmology 1979; 86: 1414-25.
8 Taylor JN. Surgery for horizontal nystagmus: AndersonKestenbaum operation. Aust J Ophthalmol 1973; 1: 114-6.

9 Kommerell G. Nystagmusoperationen zur Korrektur verschiedener Kopfzwagshaltungen. Klin Monatsbl Augenheilkd 1974; 164: 172-91.

10 Berad PV, Spielmann A, Reydy R. L'operation du fil de Cuppers. Bull Soc Ophtalmol Fr 1977; 76: 1111-6.

11 Spielmann A. Le traitement chirurgical du nystagmus. Arch Ophtalmol (Paris) 1977; 37: 751-63. 